\title{
Impact modification of PP/wood composites: A new approach using hybrid fibers
}

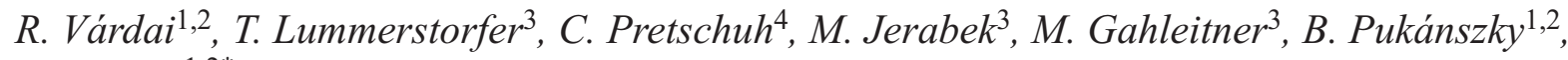 \\ K. Renner ${ }^{1,2 *}$ \\ ${ }^{1}$ Institute of Materials and Environmental Chemistry, Research Centre for Natural Sciences, Hungarian Academy of \\ Sciences, H-1519 Budapest, P.O. Box 286, Hungary \\ ${ }^{2}$ Laboratory of Plastics and Rubber Technology, Department of Physical Chemistry and Materials Science, Budapest \\ University of Technology and Economics, H-1521 Budapest, P.O. Box 91, Hungary \\ ${ }^{3}$ Borealis Polyolefine GmbH, St.-Peter-Strasse 25, A-4021 Linz, Austria \\ ${ }^{4}$ Competence Centre for Wood Composites and Wood Chemistry (Wood K plus), Division Biobased Composites and \\ Processes; Altenberger Strasse 69, 4040 Linz, Austria
}

Received 14 June 2018; accepted in revised form 2 October 2018

\begin{abstract}
The impact resistance of polypropylene (PP)/wood composites was improved either by the traditional approach of adding an elastomer or by the use of poly(ethylene terephthalate) (PET) fibers. Composites were prepared with various elastomer and PET fiber contents at a constant wood content of $20 \mathrm{wt} \%$ for all hybrid composites. Interfacial adhesion was improved by the addition of a maleic anhydride modified PP (MAPP). The components were homogenized in a twin-screw compounder and injection molded into standard tensile bars. Properties were characterized by tensile and impact testing, while scanning electron microscopy (SEM) was applied for studying the structure. A combination of acoustic emission measurements (AE) and SEM was used to understand local deformation processes, the results showing that the traditional route of impact modification with elastomers does not work in wood reinforced PP, since the simultaneous fracture of large wood particles and the cavitation of the elastomer result in limited fracture toughness. On the other hand, polymeric fibers (PET) increase the impact resistance of rigid PP homopolymer matrices reinforced with wood fibers, because they initiate new local deformation processes. The concept of using polymeric fibers for the impact modification of rigid PP/wood composites is an efficient way to extend the field of application of such reinforced materials.
\end{abstract}

Keywords: polymer composites, impact modification, hybrid composites, wood reinforcement, damage mechanism

\section{Introduction}

In the last few decades, increased interest has been shown by both academia and industry for materials based on renewable resources. The basic driving force to use and produce more materials based on natural resources was initiated by a strong drive towards increased environmental protection and sustainability. Public opinion regarding the plastics industry decayed quickly as plastics pollution became more and more conspicuous. In the late nineties, the research on both polymers and additives derived from natural resources started to gain importance [1,2]. New polymers based on naturally occurring monomers, such as poly(lactic acid) [3] or biopolymers like poly(hydroxy butyrate) produced by microorganisms have been studied intensively $[4,5]$, although neither of them has become a commodity polymer so far. On the other hand, natural fillers and fibers could at least partially replace traditional fillers in polymeric composite materials thus their utilization has grown rapidly. Wood flour was one of the first representatives of these materials in the European and North American 
regions as a new, natural-based reinforcement $[6,7]$. Wood flour-reinforced plastics (WPCs) are mostly used in structural applications, in which stiffness and strength have substantial importance [8-10]. Stiffness usually increases as a result of the addition of wood fibers into a polymer matrix [11-15]. The strength of WPCs' cannot be predicted easily, as it depends on numerous factors: the particle characteristics of wood (size, shape), the inherent strength of the natural reinforcement [16], the orientation of fibers [17] and interfacial interactions $[18,19]$. For some applications, especially in the automotive industry, the impact resistance of composite parts is also a crucial factor. A routine approach for the impact modification of rigid polymers is the addition of elastomers [20-22]. In polypropylene matrices, mostly ethylene-propylene (EPR) or ethylene-propylene-diene (EPDM) copolymers are applied as impact modifiers. The presence of an elastomer in the heterogeneous polymer system decreases stiffness, which can be compensated by the addition of fillers. Two boundary structures can form in such three-component materials: the elastomer can encapsulate the reinforcement to create an embedded structure [23-26] or the two components can be distributed separately from each other in the polymer matrix [27-29]. Only a few papers have been published on the behavior of multicomponent materials containing wood fibers. Clemons [30] carried out a model study on the recycling of PP/PE blends, and embrittlement of the blends, especially the tougher, HDPE-rich blends was observed by the addition of wood. Oksman [31], Oksman and Clemons [32] used functionalized elastomers to modify the structure and properties of $\mathrm{PP} /$ wood composites. Maleated elastomers have been found to be effective impact modifiers in wood reinforced PP composites, but notched impact strength increased only twofold compared to the unmodified composites while modulus decreased. Impact modification trials on wood reinforced PP started immediately as soon as these materials appeared on the market. Park and Balatinecz [33] used different amounts of EPDM as impact modifier in pulp fiber reinforced PP. Above $30 \mathrm{wt} \%$ wood content brittle fracture was observed even if as much as $50 \mathrm{wt} \%$ of elastomer was added to the composites. Iwamoto et al. [34] prepared wood flour and lignocellulose nanofiber reinforced PP composites and investigated their impact modification with ethylene-butylene copolymers. Although impact resistance increased with the addition of the copolymers in both cases, the actual values of notched Izod impact strength were below that of any commercial three-component PP composite.

The effect of structure on the deformation processes and impact resistance of ternary composites has been investigated in our previous study [35] as well. The structure of PP/elastomer/wood composites could be manipulated by the use of functionalized polymers. Although wood flour slightly increased impact resistance in PP and the addition of elastomers improved this property significantly, fracture toughness remained limited in all three-component hybrid systems. The results showed that the fracture of large wood particles was the dominating deformation process, which does not consume much energy. The elastomer added was expected to improve plastic deformation, thus increasing energy absorption, but its extensive cavitation took place in the studied system and even at higher elastomer amounts no shear yielding was observed. In order to achieve increased impact resistance, local deformation processes must be controlled obviously to increase the plastic deformation of the matrix polymer.

Another option to improve impact strength is to use long fibers for reinforcement. Spahr et al. [36] investigated the fracture behavior of short and long fiber reinforced PP composites as a function of fiber volume fraction. It was found that longer fibers generally increase the toughness of the materials. KargerKocsis [37] compared the properties short and long glass fiber composites as well and demonstrated significantly larger impact resistance for the latter. The failure analysis of the composites revealed that short fibers are predominantly pulled out while long fibers fracture when the crack cross them during impact. However, the length of traditional rigid fiber reinforcement, like glass or carbon fibers, is limited by fiber attrition caused by the significant shear forces acting during injection molding [38]. Polymer fibers are less exposed to fiber attrition during processing due to their lower stiffness. Self-reinforced composites consist of fibers and matrix from the same polymer. Although self-reinforced composites have excellent properties their processing is difficult because of the adjacent melting point of the fiber and matrix [39]. To avoid fiber length degradation during processing various synthetic low bending modulus fibers can be used. Zbončák and Jančář [40] reported the unique enhancement of fracture resistance of poly(methyl methacrylate) (PMMA) using poly(p-phenylene-2,6- 
benzobisoxazole) (PBO) fibers. The PBO fibers remained effective impact modifiers in hybrid PMMA composites where carbon fiber was used as another reinforcement. Sobczak et al. [41] showed that polymer fibers do not fragment considerably during processing, and fibers with several mm length can be observed in the product after extrusion and injection molding. The local deformation processes related to poly(vinyl alcohol) (PVA) fibers were fiber pull-out or fracture depending on the strength of interfacial adhesion. Both processes were able to improve the impact resistance of neat PP greatly. It was reported earlier that recycled PET fibers can also improve the impact resistance of PP for some extent [42]. Unfortunately, only the unnotched impact resistance was investigated by Santos et al. [42], thus limited information is provided on the crack propagation and resistance of PP/PET composites. However, since many authors investigated the effect of polymer fibers on the mechanical properties of PP composites our aim was slightly different. The goal of the study was to investigate of the effect of PET fibers on the impact resistance of PP/wood composites, the identification of the deformation and failure mechanisms occurring during deformation, and the development of guidelines for the preparation of structural materials with large stiffness and impact strength.

\section{Experimental}

A PP homopolymer (hPP, $M F R=50 \mathrm{~g} / 10 \mathrm{~min}$ at $230^{\circ} \mathrm{C}$ and $2.16 \mathrm{~kg}$ load) and a reactor blend (ePP, $M F R=50 \mathrm{~g} / 10 \mathrm{~min}$ at $230^{\circ} \mathrm{C}$ and $2.16 \mathrm{~kg}$ load) were used as matrix polymers in this study. Both were supplied by Borealis $\mathrm{GmbH}$, Austria. In order to study the effect of elastomer content, the Dutral CO038PL ethylene-propylene copolymer with an ethylene content of $72 \mathrm{wt} \%$ and a Mooney viscosity, ML (1+4), of 60 measured at $125^{\circ} \mathrm{C}$ from Polimeri Europa, Italy was added to the reactor blend. The reactor blend was diluted with the homopolymer in order to obtain copolymers with smaller elastomer content than $33 \mathrm{wt} \%$. A maleated PP polymer was applied to improve interfacial adhesion. The Scona 2112 grade with an $M F R$ of $2.7 \mathrm{~g} / 10 \mathrm{~min}\left(190^{\circ} \mathrm{C}, 2.16 \mathrm{~kg}\right)$ and maleic anhydride (MAH) content of $0.9-1.2 \%$ supplied by BYK Chemie GmbH, Switzerland was added at $10 \mathrm{wt} \%$ in case of wood while $20 \mathrm{wt} \%$ in case of PET fibers, calculated for the amount of the reinforcement. The wood flour (EFC1000) was supplied by Rettenmaier and Söhne GmbH, Germany.
The average particle size of the fillers was $160 \mu \mathrm{m}$ and their aspect ratio was about 6.8. The elastomer (EPR) content of the composites was 0, 20, 33 and $43 \mathrm{wt} \%$ calculated for the matrix polymer. Wood content changed from 0 to $40 \mathrm{wt} \%$ in 7 steps related to the total weight of the composites. Polyester short cut fibers (PET Type 713, lot 699) with $22 \mu \mathrm{m}$ diameter and $4.4 \mathrm{~mm}$ length were obtained from Performance Fibers $\mathrm{GmbH}$, Germany. PET fiber content changed from 0 to $50 \mathrm{wt} \%$ in 7 steps in homopolymer matrices, while from 0 to $30 \mathrm{wt} \%$ in PP/PET/ wood composites. Hybrid composites either with elastomer (PP/elastomer/wood) or with polymer fibers (PP/PET/wood) contained $20 \mathrm{wt} \%$ wood flour at changing elastomer or PET fiber content. The composition of the investigated $\mathrm{PP} / \mathrm{PET}, \mathrm{PP} /$ wood and hybrid composites is collected in Table 1.

The components were homogenized using a Brabender DSK 42/7 twin-screw compounder at 180-190$200-200^{\circ} \mathrm{C}$ and $40 \mathrm{rpm}$ followed by granulation. The granules were extruded a second time to improve homogeneity. Before composite preparation wood flour was dried in an air circulating oven $\left(105^{\circ} \mathrm{C}\right.$ for $\left.4 \mathrm{~h}\right)$. Standard universal specimens (ISO 527 1A) were injection molded (Demag IntElect 50/330-100) at 170 180-190-200 ${ }^{\circ} \mathrm{C}$ barrel and $40^{\circ} \mathrm{C}$ mold temperature, 550 bar injection and 500 bar holding pressure with 30 s holding time.

Tensile testing was carried out using an Instron 5566 type machine (Instron Co., Canton, OH, USA). Modulus, tensile strength and elongation-at-break were derived from recorded stress vs. strain traces. Local deformation processes were followed by acoustic emission measurement carried out with a Sensophone AED 40/4 apparatus. The structure of the composites and deformation processes were studied by scanning electron microscopy using a Jeol JSM 6380 LA apparatus (JEOL Ltd., Tokyo, Japan). Micrographs were recorded on fracture surfaces created during tensile testing. Notched Charpy impact resistance was determined according to the ISO 179 standard at $23^{\circ} \mathrm{C}$ with $2 \mathrm{~mm}$ notch depth. Instrumented impact testing was carried out using a Ceast Resil 5.5 instrument (CEAST spa, Pianezza, Italy) with a 4 J hammer.

\section{Results and discussion}

\subsection{Impact resistance and tensile properties}

Modification with elastomers is a very effective method for the improvement of the impact properties 
Table 1. Composition of the investigated PP/PET, PP/wood and PP/PET/wood hybrid composites.

\begin{tabular}{|c|c|c|c|c|c|c|}
\hline \multirow{2}{*}{ Composites" } & \multicolumn{2}{|c|}{ PET fiber content } & \multicolumn{2}{|c|}{ Wood fiber content } & \multicolumn{2}{|c|}{ Elastomer content } \\
\hline & {$[\mathrm{wt} \%]$} & {$[\mathbf{v} / \mathbf{v} \%]$} & {$[w t \%]$} & {$[\mathrm{v} / \mathbf{v} \%]$} & {$[w t \%]$} & {$[\mathrm{v} / \mathbf{v} \%]$} \\
\hline \multirow{9}{*}{ PP/PET } & 0 & 0.00 & & & & \\
\hline & 5 & 3.27 & & & & \\
\hline & 10 & 6.67 & & & & \\
\hline & 15 & 10.19 & & & & \\
\hline & 20 & 13.85 & & & & \\
\hline & 25 & 17.65 & & & & \\
\hline & 30 & 21.60 & & & & \\
\hline & 40 & 30.00 & & & & \\
\hline & 50 & 39.13 & & & & \\
\hline \multirow{7}{*}{ PP/wood } & & & 5 & 3.06 & & \\
\hline & & & 10 & 6.25 & & \\
\hline & & & 15 & 9.57 & & \\
\hline & & & 20 & 13.04 & & \\
\hline & & & 25 & 16.67 & & \\
\hline & & & 30 & 20.45 & & \\
\hline & & & 40 & 28.57 & & \\
\hline \multirow{6}{*}{ PP/PET/wood } & 5 & 3.27 & 20 & 13.04 & & \\
\hline & 10 & 6.67 & 20 & 13.04 & & \\
\hline & 15 & 10.19 & 20 & 13.04 & & \\
\hline & 20 & 13.85 & 20 & 13.04 & & \\
\hline & 25 & 17.65 & 20 & 13.04 & & \\
\hline & 30 & 21.60 & 20 & 13.04 & & \\
\hline \multirow{3}{*}{ PP/elastomer } & & & & & 20 & 21.18 \\
\hline & & & & & 33 & 34.61 \\
\hline & & & & & 43 & 44.78 \\
\hline \multirow{3}{*}{ PP/elastomer/wood } & & & 20 & 13.04 & 16 & 17.39 \\
\hline & & & 20 & 13.04 & 26 & 28.69 \\
\hline & & & 20 & 13.04 & 34 & 37.39 \\
\hline
\end{tabular}

* composites were prepared with and without MAPP, the amount of incorporated MAPP was $20 \mathrm{wt} \%$ of PET fiber content and $10 \mathrm{wt} \%$ of wood fibers.

of rigid polymers. Ethylene-propylene copolymers can be incorporated into PP matrices during processing, but heterophasic copolymers are also available on the market, in which propylene is polymerized in the presence of small amount of ethylene resulting in a complex structure [43] and good impact resistance. The notched Charpy impact strength of polypropylene as a function of additive content is shown in Figure 1. The effect of three different additives on fracture toughness are compared in the figure. As stated earlier, wood influences the impact of homopolymer PP only slightly. Limited impact resistance and brittle fracture can be observed independently of wood content and the strength of interfacial adhesion. Although the addition of MAPP increases interfacial adhesion considerably, it does not influence impact strength (compare full and empty symbols). On the other hand, the modification of the homopolymer with an elastomer has an outstanding effect on impact resistance above 20 vol\% elastomer content. However, this effect disappears when wood is also incorporated into the PP/elastomer blends as a consequence of the restricted plastic deformation of the matrix, as shown in our previous study [35]. In Figure 1 , moderate increase in impact resistance can be observed in composites modified with PET fibers. Fibers have similar effect on this property in both the presence and absence of the coupling agent. It is worth noting that apparently the elastomer and the polymer fiber have the same effect on impact resistance at around $20 \mathrm{vol} \%$ additive content.

Besides impact strength, stiffness is another important mechanical property of composites for automotive applications. Wood increases the stiffness of PP, which is not influenced very much by interfacial adhesion [44]. Polymeric fibers, like polyethylene-terephthalate, 


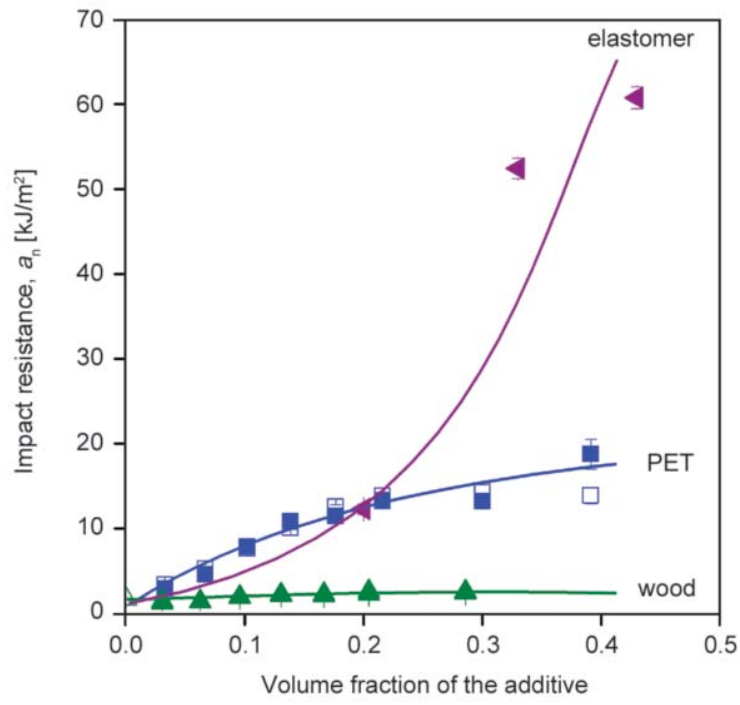

Figure 1. Composition dependence of the impact resistance of the PP homopolymer with different modifiers. Symbols: 4, $\square, \triangle$ with MAPP, $\square, \triangle$ without MAPP, $<$ elastomer, $\square, \square$ PET fiber, $\Delta, \triangle$ wood flour.

increase stiffness as well, but to a lesser extent compared to wood (Figure 2). Depending on the type of the wood fiber and the direction of the load, the modulus of wood particles can vary between 10 and $40 \mathrm{GPa}$, while the modulus of PET fibers is not more than $3 \mathrm{GPa}$. Nevertheless, besides improving impact resistance, these fibers increase also the stiffness of PP composites. The opposite is true for elastomer modification, since the soft elastomer particles decrease the stiffness of the polymer composition significantly.

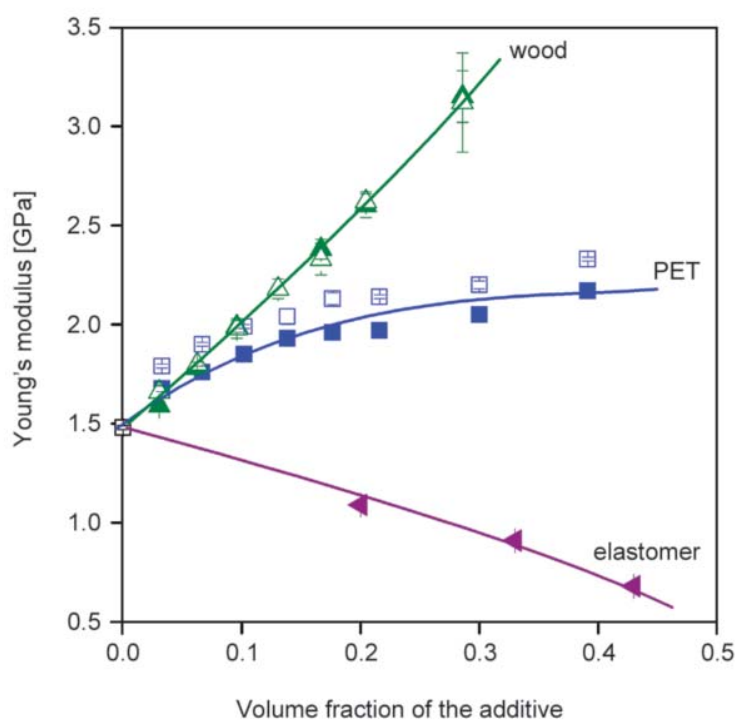

Figure 2. Effect of composition and the type of the additives on the stiffness of the PP homopolymer. Symbols: $<, \square, \Delta$ with MAPP, $\square, \triangle$ without MAPP, $<$ elastomer, $\square, \square$ PET fiber, $\Delta, \triangle$ wood flour.

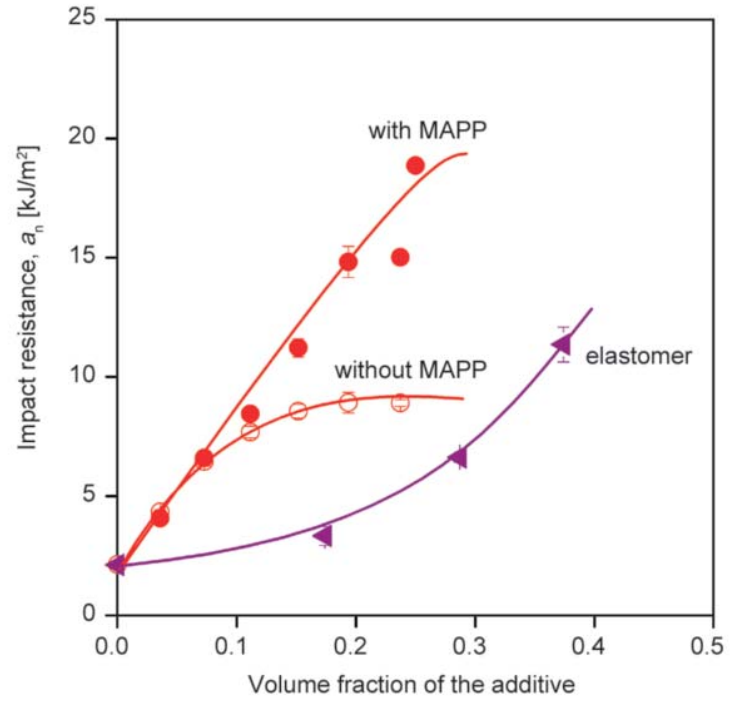

Figure 3. Dependence of the impact resistance of PP/PET/ wood and PP/elastomer/wood hybrid composites on the amount of the modifier. Wood content: $20 \mathrm{wt} \%$. Symbols: ${ }^{\circ}$, O PET, < elastomer.

In Figure 3, impact resistance is presented as a function of additive content for hybrid composites containing $20 \mathrm{wt} \%$ wood flour. The incorporation of an elastomer or the use of a heterophasic PP matrix improves the notched impact strength of wood reinforced PP composites. However, elastomers are efficient only at relatively large volume fractions and the actual values of impact resistance are still below expectations. Polymer fibers, on the other hand, increase impact resistance already at small fiber contents, and larger impact resistance is achieved with their use at 20 and even at $30 \mathrm{vol} \%$ additive content than with elastomer modification. In spite of the limited effect of the MAPP coupling on the stiffness and impact resistance of PP/PET binary composites, its influence is significant in PP/PET/wood hybrid composites. We may assume that fiber-related processes like fiber pull-out or fracture increase the fracture toughness of PP/wood composites. Nevertheless, increased adhesion achieved by the coupling agent clearly results in larger impact strength as shown by Figure 3.

Impact modifiers usually influence the deformability of the composites as well, and the amount of energy absorbed during impact depends on the extent of the plastic deformation of the polymer matrix. Elongation-at-break values are shown in Figure 4 for the different hybrid composites. The deformability of the homopolymer matrix is around $450 \%$, and the addition of $20 \mathrm{wt} \%$ wood fibers clearly decreases it considerably. These small elongation-at-break values 


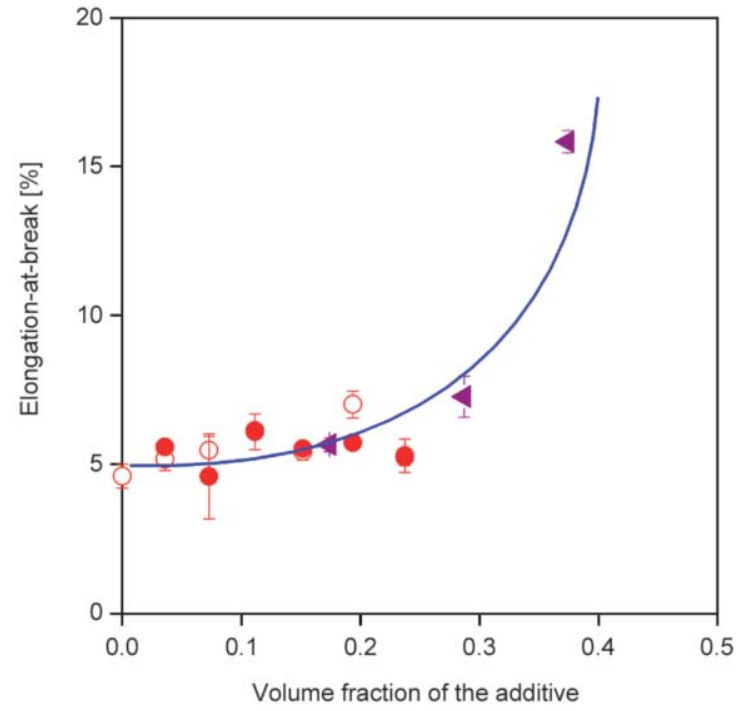

Figure 4. Effect of additive content on the deformability of $\mathrm{PP} /$ wood composites modified with PET fibers or an elastomer. Wood content: $20 \mathrm{wt} \%$. Symbols: $\bigcirc, \mathrm{PET}, \triangleleft$ elastomer.

are closely related to the limited impact strength of wood reinforced polymer composites. Large wood particles debond from the matrix or fracture internally [45], depending on the strength of interfacial interactions. The addition of polymer fibers does not influence the deformability of PP/wood composites, although in most cases the incorporation of large amounts of filler or fiber decreases elongation further. The negative effect of wood particles on deformability can be compensated only by relatively large amounts of elastomer as demonstrated by Figure 4. The dissimilar effect of PET fibers and elastomers, respectively, cannot be explained without the detailed analysis of the deformation processes taking place during deformation and fracture.

\subsection{Local deformation processes}

Instrumented impact testing offers valuable information about the fracture process. The force vs. time traces can be divided into two parts related to the initiation and the propagation of the crack. The corresponding force vs. time traces are presented in Figure 5 for composites with $20 \mathrm{wt} \%$ wood reinforcement and $20 \mathrm{wt} \%$ impact modifier (PET fibers or elastomer). The respective trace of a $\mathrm{PP} /$ wood composite without any additive is also included in the graph as reference. After reaching the critical force at which fracture is initiated (peak force), the twocomponent $\mathrm{PP} /$ wood composite fails with rapid crack propagation, during which no additional energy is

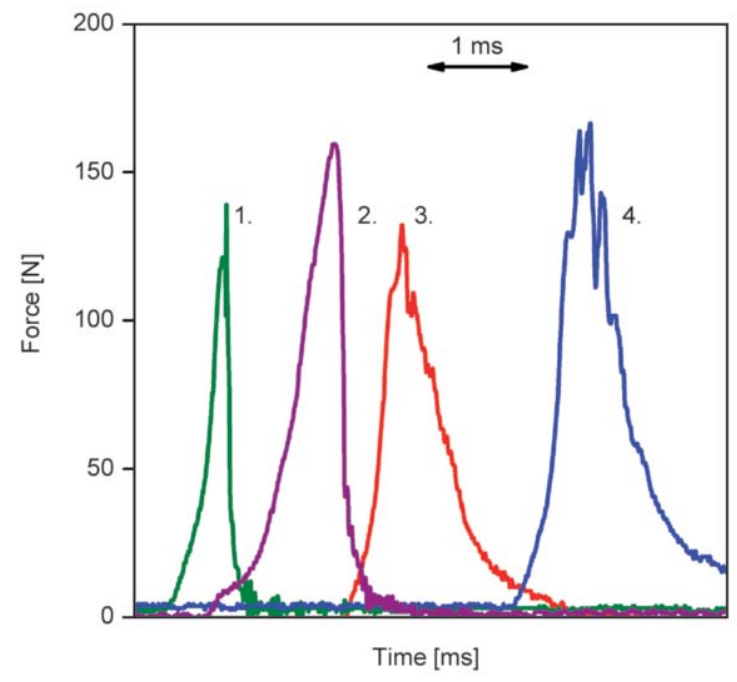

Figure 5. Force vs. time traces recorded by instrumented impact testing of PP/wood composites. Notched Charpy impact. Wood content: $20 \mathrm{wt} \%$. 1. PP/wood, 2. PP/elastomer/wood (elastomer content: $26 \mathrm{wt} \%$ ), 3. PP/PET/wood (PET content: $20 \mathrm{wt} \%$ ), 4. PP/ PET/wood/MAPP (PET content: $20 \mathrm{wt} \%$ ).

consumed. The crack is initiated at larger maximum force for the PP/wood composite modified with elastomer, which indicates that the initiation of crack is hindered by the presence of the elastomer phase. Nevertheless, the second process, i.e. crack propagation, is rather similar to that of the unmodified composite proving again that only limited plastic deformation takes place in the elastomer modified composite resulting in poor impact resistance. The larger impact resistance of PP/PET/wood hybrid composites is reflected also in the traces recorded by instrumented impact testing. Although the maximum force, i.e. crack initiation, is similar to that of the elastomer modified composite, crack propagation is slower and much more energy is absorbed during fracture.

The conclusions about the effect of PET fibers on impact resistance were confirmed by the results of instrumented impact testing. The role of polymer fibers in the deformation processes taking place during the failure of the PP homopolymer and the hybrid composites was investigated also by acoustic emission measurements. The stress vs. strain trace of the PP homopolymer containing $20 \mathrm{wt} \%$ PET fiber and the MAPP coupling agent is plotted in Figure $6 \mathrm{a}$ together with the results of the acoustic emission measurement. A considerable number of acoustic events occurs at very small deformations in this composite (see small circles), and no further signals are detected after the yielding of the specimen. The 
height of the individual signal represents the amplitude of the signal, but the scale is not shown (from 20 to $100 \mathrm{~dB}$ ). The shape of the cumulative number of signals (hits) trace which consists mainly low amplitude signals detected indicates that principally debonding or fiber pull-out takes place during fracture [45], and PET fibers do not fracture in the homopolymer matrix, in spite of the improved adhesion resulting from the presence of MAPP. The cumulative number of hits trace and the distribution of the amplitudes of individual signals recorded in the PP/wood composite with good adhesion (Figure $6 \mathrm{~b}$ ) differs to a great extent from that of the $\mathrm{PP} / \mathrm{PET}$ composite. Previous results confirmed [46] that in these composites wood particles fracture under the effect of external load. The continuous increase in the cumulative number of hits trace indicates the fracture of large wood particles [16], but a small amount of debonding also occurs at small deformations. Signals with large amplitudes can be associated with the internal fracture of wood particles. The results of acoustic emission testing are presented in Figure $6 \mathrm{c}$ for the PP/PET/ wood composite. Compared to the previous two graphs, the cumulative number of hit traces indicates the fracture of fibers or particles with some debonding at small strain values. The debonding or fiber pull-out of PET fibers cannot be identified in the trace as clearly as in Figure $6 \mathrm{a}$. The number of detected signals is slightly larger than in the PP/wood or PP/PET composites, but both reinforcements are present in the hybrid composites thus the total additive content (fiber and filler) is $40 \mathrm{wt} \%$ in the composite presented in Figure $6 \mathrm{c}$.

Not only the shape of the cumulative number of hit traces, but also the quantitative evaluation of the acoustic emission results can be useful for the identification of the dominating deformation process. A previous study showed that very close correlation exists between the initiation stress of the dominating local deformation process and composite strength proving that local processes often lead to the failure of the composite $[16,45]$. The process related to the PET fibers start already at a very small stress and largely finish before yielding occurs, thus we cannot expect a good correlation between the stress necessary to initiate this process and the tensile strength of the composites. Additional information about local deformation processes can be obtained from the analysis of the number of signals detected during the
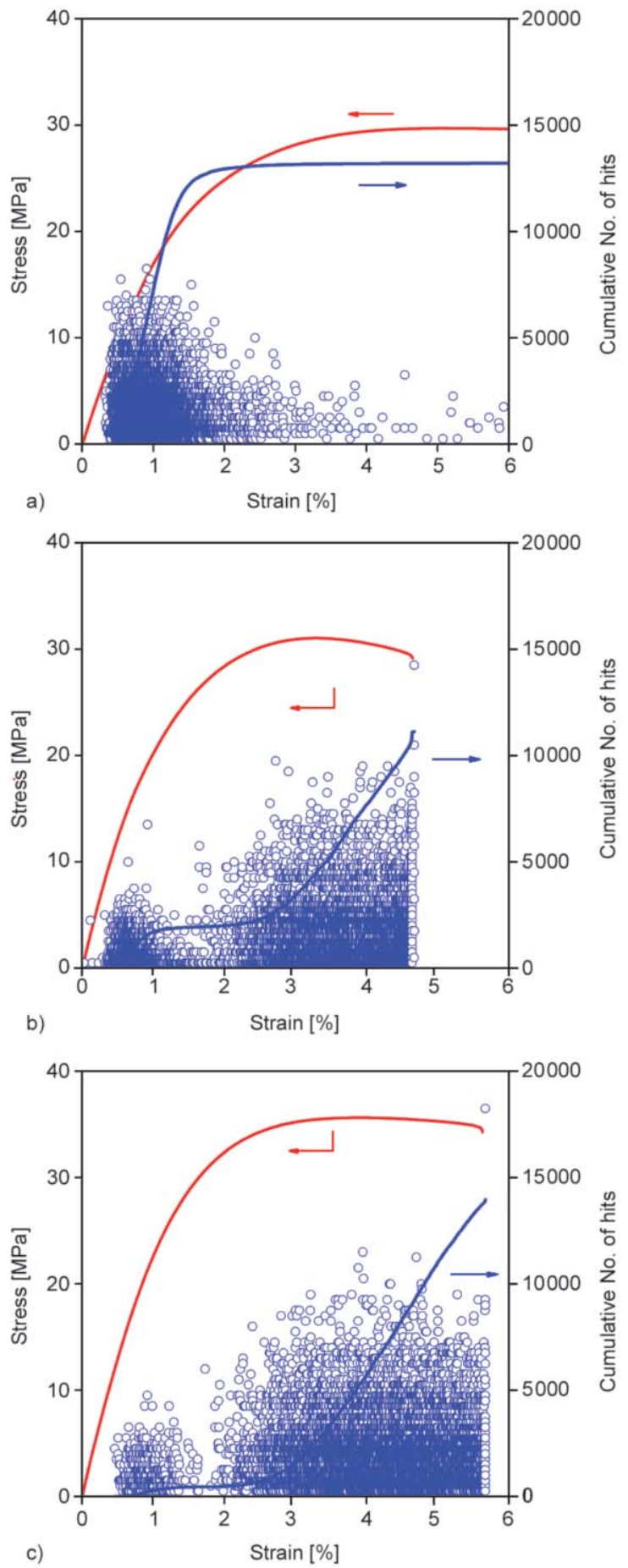

Figure 6. Results of the acoustic emission testing of a) PP/ PET composite with MAPP containing $20 \mathrm{wt} \%$ of the fibers. Small circles indicate individual signals; the $\mathrm{S}$ shape curve is the cumulative No. of signals trace (right axis). The stress vs. strain correlation is added for reference (left axis). b) PP/wood composite with good adhesion (MAPP) containing $20 \mathrm{wt} \%$ of wood. Symbols and traces are the same as in Figure 6a. c) PP/PET/wood hybrid composite with MAPP containing $20 \mathrm{wt} \%$ PET fiber and $20 \mathrm{wt} \%$ wood flour. Symbols and traces are the same as in Figure 6a. 
deformation of the specimen. The total number of hits recorded until the failure of the specimen is plotted as a function of filler content for the $\mathrm{PP} /$ wood and PP/PET/wood composites in Figure 7.

Composites without the coupling agent generate more signals during their deformation than those with MAPP. The largest number of signals were detected in the case of PET fiber reinforced composites in the absence of MAPP (see Figure 7). A similar number of signals was recorded in the PP/PET/wood hybrid and $\mathrm{PP} / \mathrm{PET}$ composites. This similarity indicates that the majority of the signals are related to the polymer fibers. Slightly fewer signals were detected in PP/ PET/wood hybrid composites with coupling agent, but PP/PET composites with MAPP generated even fewer signals. We can assume that large number of acoustic signals are recorded when the pull-out of PET fibers takes place and significantly less when adhesion is improved by the coupling agent. It is worth to note that hybrid composites with MAPP generated much more signals than PP/PET composites with MAPP, thus the presence of wood particles change the dominating deformation process in hybrid composites.

Scanning electron micrographs recorded on the facture surface of specimens provides a deeper insight into the nature of the deformation processes leading to the failure of the composites. SEM micrographs taken from fracture surfaces created during tensile testing are presented in Figure 8. Extensive pull-out

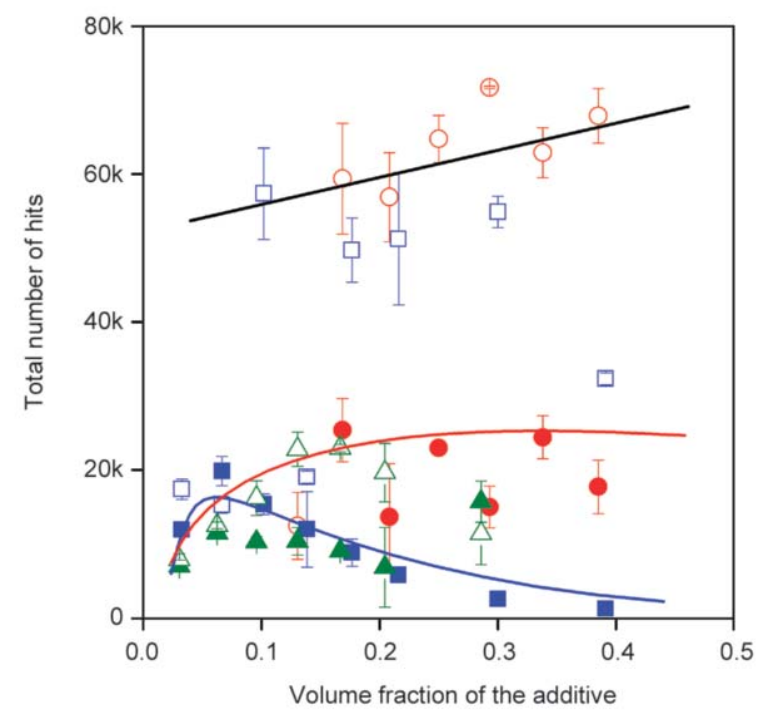

Figure 7. The total number of signals detected during the deformation and failure of $\mathrm{PP} /$ wood and PP/PET/ wood composites. Symbols: $\square, \square$ PET fiber, $\Delta, \triangle$ wood flour, $\bigcirc$, O PET/wood hybrid; empty symbols: without coupling, full symbols: with coupling. of PET fibers can be seen in the micrograph presented in Figure 8a, in spite of the improved adhesion of the components. Extensive plastic deformation of the matrix is also initiated by the debonding of the polymer-fiber interface. The length of the fibers pulled out depends on the strength of the fibers and on interfacial adhesion. Fiber attrition during processing could also decrease the initial length of fibers, but PET fibers have lower stiffness with several order of magnitude than glass or carbon fibers, thus much less shortening takes place and fibers bend easier. Since the fracture of PET fibers cannot be identified in PP/PET composites with MAPP, we must conclude that fiber pull-out takes place in the PP/PET composites with and without MAPP as well. However, the extent of fiber pull-out (length and number of fibers) must be different in the two cases, as indicated by the number of signals detected by acoustic emission (Figure 7). The fracture surface of a PP/PET/wood hybrid composite with MAPP shows a very similar picture (see Figure $8 b$ ). The pull-out of PET fibers is evident, but some fractured PET fibers can be observed on the surface as well. A more detailed analysis would be needed to determine the ratio of fractured and pulled out fibers. At this point we can conclude that the improved adhesion of short PET fibers initiates a further process or processes compared to PET reinforced composites without MAPP that could account for the larger impact strength. Although the image presented in Figure $8 \mathrm{~b}$ has been selected from a larger set recorded on the fracture surfaces of a number of specimens, wood particles could not be found in any of the micrographs. Earlier studies proved that, depending on the strength of interfacial interaction, large wood particles either fracture or debond from the matrix $[45,46]$. The acoustic emission traces of PP/PET/wood composites containing MAPP (Figure 6c) seemed to be identical to the traces of PP/wood composites with MAPP (Figure 6b) indicating that wood particles fracture also in the hybrid composites, but this process was not confirmed by the SEM micrographs.

\subsection{Discussion and practical consequences}

We have shown in the previous section that several local deformation processes take place during the fracture of hybrid PP composites. The results showed that the impact resistance of PP/PET/wood composites is determined by processes related to the polymer fiber reinforcement. The composition dependence of 


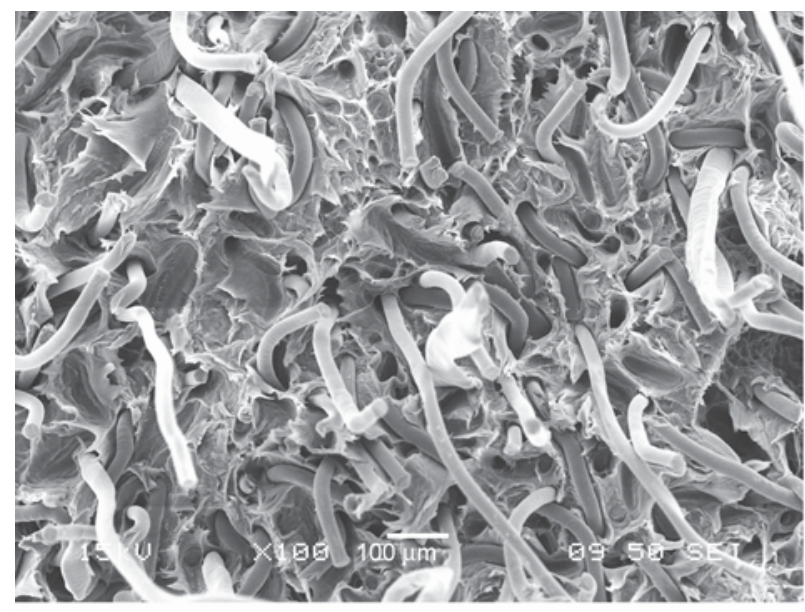

a)

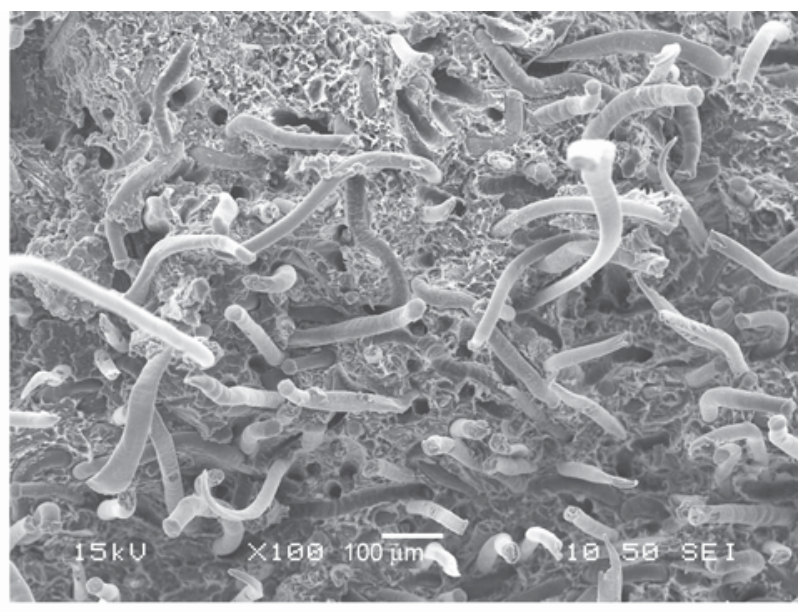

Figure 8. A SEM micrograph taken from the fracture surface of specimens created during the tensile testing of a) PP/PET composite with MAPP. Composition: $25 \mathrm{wt} \%$ PET. b) PP/PET/wood hybrid composite with MAPP. Composition: $25 \mathrm{wt} \%$ PET, $20 \mathrm{wt} \%$ wood.

the tensile strength of PP/wood and PP/PET composites is presented in Figure 9. The strength of PP/wood hybrid composites modified with an elastomer or with PET fibers are also included in the figure. The largest strength can be achieved with the combination of wood reinforcement and coupling. Compared to wood, PET fibers are less efficient in reinforcing PP in spite of their larger aspect ratio. The strength of hybrid composites changes only slightly with increasing PET fiber content. Hybrid composites containing MAPP have comparable tensile strength to $\mathrm{PP} /$ wood composites (with MAPP) with the same wood content (20 wt $\%$ ). The correlation is very similar for composites not containing the coupling agent; wood reinforces PP the most, while the strength of the hybrid composites and PP containing the neat PET fibers changes similarly as a function of additive content. Although the elastomer increases the impact resistance of $\mathrm{PP} /$ wood composites, composite strength decreases considerably because of the increasing amount of soft phase incorporated into the composite.

An inverse correlation exists between impact resistance and stiffness for most structural materials. One of the most important goals of composite development is to increase both characteristics at the same time, or at least improve one without sacrificing the other. The impact resistance of the materials investigated in our present study is plotted against their Young's modulus in Figure 10. Three different correlations can be observed in the figure. Wood increases stiffness significantly, but does not affect the impact resistance of the homopolymer matrix. On

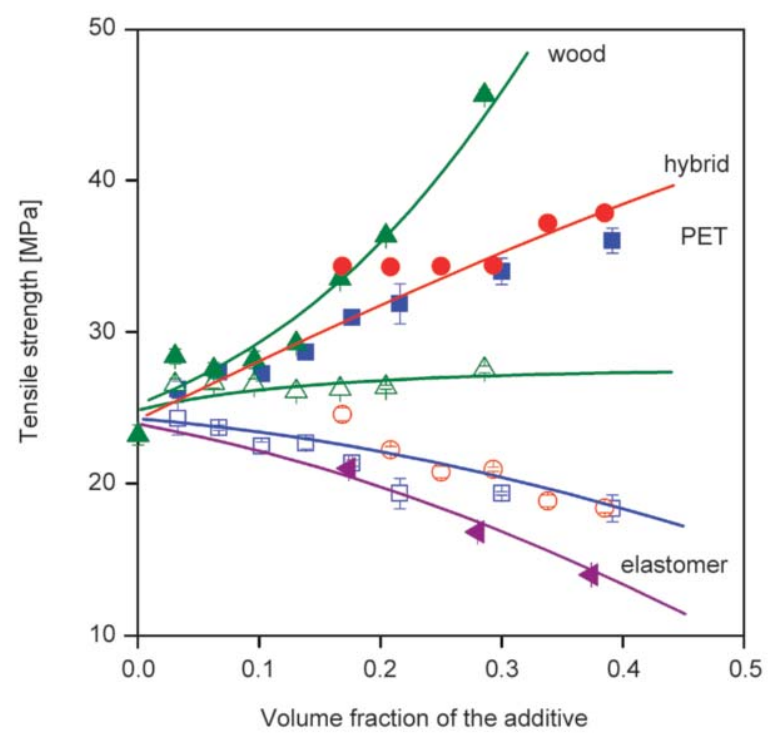

Figure 9. Effect of additive content and adhesion on the tensile strength of PP composites. Symbols: $\square, \square$ PET fiber, $\Delta, \triangle$ wood flour, $\bigcirc, \bigcirc$ PET/wood hybrid, 4 elastomer/wood; empty symbols: without coupling, full symbols: with coupling.

the other hand, elastomer modification improves impact resistance of PP considerably when wood content is small, but toughness decreases drastically with increasing stiffness, i.e. with increasing wood content. Unfortunately, the impact resistance of the elastomer modified $\mathrm{PP} /$ wood composites is rather small above $1.5 \mathrm{GPa}$ modulus. PET fibers slightly increase the modulus of the PP homopolymer (see Figure 2), improving the impact resistance of both the neat polymer and the $\mathrm{PP} /$ wood composites. As a result, a different correlation can be observed between the stiffness and impact resistance of PP/PET/ wood hybrid 


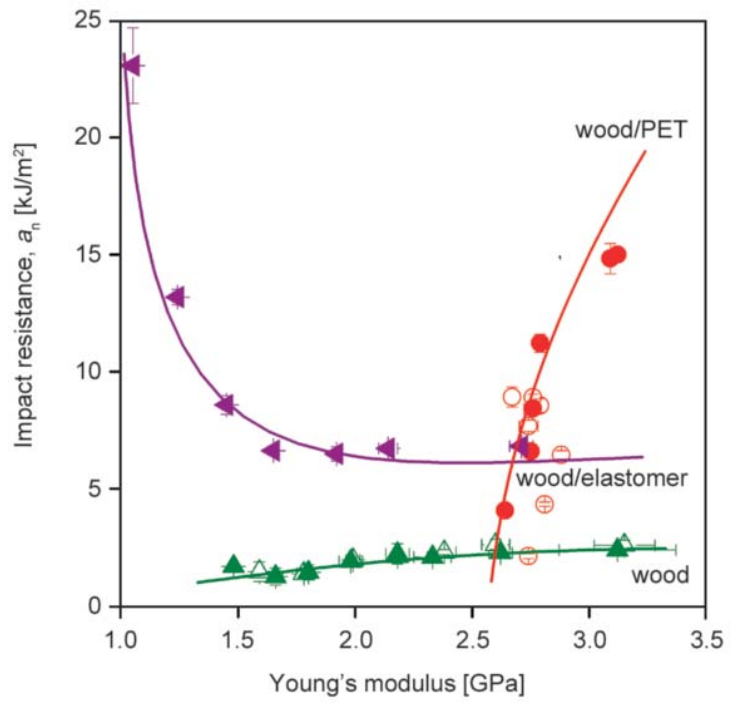

Figure 10. Correlation between the notched Charpy impact resistance and the stiffness of some of the composites investigated in this study. Symbols: $\Delta, \triangle$ wood flour, $\bigcirc, \bigcirc \mathrm{PET} /$ wood hybrid, $<$ elastomer/wood; empty symbols: without coupling, full symbols: with coupling.

composites in Figure 10. PET fibers increase the notched impact resistance of $\mathrm{PP} /$ wood composites considerably, while slightly increase also their stiffness. The approach and the relationship may provide a new class of materials for many industrial applications.

\section{Conclusions}

The results of the experiments carried out on twoand three-component wood fiber reinforced PP composites showed that the traditional route of impact modification does not work well in these materials. Although in neat polypropylene as well as in composites with mineral fillers the elastomer improves impact strength considerably especially at large elastomer contents, the approach does not work in wood reinforced composites. The simultaneous fracture of large wood particles and the cavitation of the elastomer used in this study results in limited fracture toughness in hybrid composites. On the other hand, polymeric fibers (PET) increase the impact resistance of rigid PP homopolymer matrices reinforced with wood fibers, because they initiate new local deformation processes. Consequently, PET fibers improve the impact resistance of PP/wood composites more efficiently already at small PET fiber content than any elastomeric impact modifier. Instrumented impact tests proved that the energy necessary for crack initiation is similar in all wood reinforced
PP composites, but long polymer fibers hinder crack propagation during fracture. Acoustic emission testing and scanning electron microscopy verified that the extensive pull-out of the PET fibers takes place independently of the strength of interfacial adhesion and wood content resulting in improved impact behavior. The concept of using polymeric fibers for the impact modification of rigid $\mathrm{PP} /$ wood composites is an efficient way to extend the field of application of such reinforced materials.

\section{Acknowledgements}

This work has partially been funded by the Austrian government via the COMET program. The research on the hybrid composite materials was financed by the National Scientific Research Fund of Hungary (OTKA Grant No. K120039 and FK112489). One of the authors (KR) is grateful also to the János Bolyai Research Scholarship of the Hungarian Academy of Sciences for its support.

\section{References}

[1] Bledzki A. K., Gassan J.: Composites reinforced with cellulose based fibres. Progress in Polymer Science, 24, 221-274 (1999).

https://doi.org/10.1016/S0079-6700(98)00018-5

[2] Mohanty A. K., Misra M., Hinrichsen G.: Biofibres, biodegradable polymers and biocomposites: An overview. Macromolecular Materials and Engineering, 276-277, 1-24 (2000). https://doi.org/10.1002/(SICI)14392054(20000301)276:1<1::AID-MAME1>3.0.CO;2-W

[3] Sawyer D. J.: Bioprocessing - No longer a field of dreams. Macromolecular Symposia, 201, 271-281 (2003).

https://doi.org/10.1002/masy.200351130

[4] Blümm E., Owen A. J.: Miscibility, crystallization and melting of poly(3-hydroxybutyrate)/poly(L-lactide) blends. Polymer, 36, 4077-4081 (1995). https://doi.org/10.1016/0032-3861(95)90987-D

[5] Pouton C. W., Akhtar S.: Biosynthetic polyhydroxyalkanoates and their potential in drug delivery. Advanced Drug Delivery Reviews, 18, 133-162 (1996). https://doi.org/10.1016/0169-409X(95)00092-L

[6] Kokta B. V., Raj R. G., Daneault C.: Use of wood flour as filler in polypropylene: Studies on mechanical properties. Polymer-Plastics Technology and Engineering, 28, 247-259 (1989). https://doi.org/10.1080/03602558908048598

[7] Myers G. E., Chahyadi I. S., Coberly C. A., Ermer D. S.: Wood flour/polypropylene composites: Influence of maleated polypropylene and process and composition variables on mechanical properties. International Journal of Polymeric Materials and Polymeric Biomaterials, 15, 21-44 (1991).

https://doi.org/10.1080/00914039108031519 
[8] Carus M., Gahle C., Korte H.: Market and future trends for wood-polymer composites in Europe: The example of Germany. in 'Wood-polymer composites' (eds.: Oksman K., Sain M.) CRC Press, Boca Raton, 300-330 (2008).

https://doi.org/10.1533/9781845694579.300

[9] Mathew A. P., Oksman K., Sain M.: Mechanical properties of biodegradable composites from poly lactic acid (PLA) and microcrystalline cellulose (MCC). Journal of Applied Polymer Science, 97, 2014-2025 (2005). https://doi.org/10.1002/app.21779

[10] Markarian J.: Wood-plastic composites: Current trends in materials and processing. Plastics, Additives and Compounding, 7, 20-26 (2005).

https://doi.org/10.1016/S1464-391X(05)70453-0

[11] Stark N. M., Rowlands R. E.: Effects of wood fiber characteristics on mechanical properties of wood/polypropylene composites. Wood and Fiber Science, 35, 167-174 (2003).

[12] Ichazo M. N., Albano C., González J., Perera R., Candal M. V.: Polypropylene/wood flour composites: Treatments and properties. Composite Structures, 54, 207 214 (2001).

https://doi.org/10.1016/S0263-8223(01)00089-7

[13] Selke S. E., Wichman I.: Wood fiber/polyolefin composites. Composites Part A: Applied Science and Manufacturing, 35, 321-326 (2004).

https://doi.org/10.1016/j.compositesa.2003.09.010

[14] Bledzki A. K., Jaszkiewicz A.: Mechanical performance of biocomposites based on PLA and PHBV reinforced with natural fibres - A comparative study to PP. Composites Science and Technology, 70, 1687-1696 (2010). https://doi.org/10.1016/j.compscitech.2010.06.005

[15] Borja Y., Rieß G., Lederer K.: Synthesis and characterization of polypropylene reinforced with cellulose I and II fibers. Journal of Applied Polymer Science, 101, 364-369 (2006)

https://doi.org/10.1002/app.23847

[16] Faludi G., Link Z., Renner K., Móczó J., Pukánszky B.: Factors determining the performance of thermoplastic polymer/wood composites; The limiting role of fiber fracture. Materials and Design, 61, 203-210 (2014). https://doi.org/10.1016/j.matdes.2014.04.052

[17] Renner K., Móczó J., Pukánszky B.: Polymer/wood composites. in 'Wiley encyclopedia of composites' (ed.: Nicolais L.) 1-19 (2012).

https://doi.org/10.1002/9781118097298.weoc180

[18] Lu J. Z., Wu Q., Negulescu I. I.: Wood-fiber/high-density-polyethylene composites: Coupling agent performance. Journal of Applied Polymer Science, 96, 93-102 (2005). https://doi.org/10.1002/app.21410

[19] Liu X. Y., Dai G. C.: Surface modification and micromechanical properties of jute fiber mat reinforced polypropylene composites. Express Polymer Letters, 1, 299 307 (2007).

https://doi.org/10.3144/expresspolymlett.2007.43
[20] Bucknall C. B., Paul D. R.: Notched impact behavior of polymer blends: Part 1: New model for particle size dependence. Polymer, 50, 5539-5548 (2009).

https://doi.org/10.1016/j.polymer.2009.09.059

[21] Bartczak Z., Argon A. S., Cohen R. E., Weinberg M.: Toughness mechanism in semi-crystalline polymer blends: I. High-density polyethylene toughened with rubbers. Polymer, 40, 2331-2346 (1999).

https://doi.org/10.1016/S0032-3861(98)00445-5

[22] Gahleitner M., Tranninger C., Doshev P.: Heterophasic copolymers of polypropylene: Development, design principles, and future challenges. Journal of Applied Polymer Science, 130, 3028-3037 (2013).

https://doi.org/10.1002/app.39626

[23] Stamhuis J. E.: Mechanical properties and morphology of polypropylene composites. Talc-filled, elastomermodified polypropylene. Polymer Composites, 5, 202207 (1984).

https://doi.org/10.1002/pc. 750050308

[24] Stamhuis J. E.: Mechanical properties and morphology of polypropylene composites II. Effect of polar components in talc-filled polypropylene. Polymer Composites, 9, 72-77 (1988). https://doi.org/10.1002/pc. 750090110

[25] Stamhuis J. E.: Mechanical properties and morphology of polypropylene composites. III. Short glass fiber reinforced elastomer modified polypropylene. Polymer Composites, 9, 280-284 (1988).

https://doi.org/10.1002/pc.750090406

[26] Pukánszky B., Kolařik J., Lednický F.: Mechanical properties of three-component polypropylene composites. in 'Polymer composites' (ed.: Sedláček B.) Walter de Gruyter, Berlin, 553-560 (1986).

[27] Kolařik J., Lednický F.: Structure of polypropylene/ EPDM elastomer/calcium carbonate composites. in 'Polymer composites' (ed.: Sedláček B.) Walter de Gruyter, Berlin, 537-544 (1986).

[28] Premphet K., Horanont P.: Influence of stearic acid treatment of filler particles on the structure and properties of ternary-phase polypropylene composites. Journal of Applied Polymer Science, 74, 3445-3454 (1999). https://doi.org/10.1002/(SICI)10974628(19991227)74:14<3445::AID-APP19>3.0.CO;2-0

[29] Hornsby P. R., Premphet K.: Influence of phase microstructure on the mechanical properties of ternary phase polypropylene composites. Journal of Applied Polymer Science, 70, 587-597 (1998).

https://doi.org/10.1002/(SICI)10974628(19981017)70:3<587::AID-APP21>3.0.CO;2-X

[30] Clemons C.: Elastomer modified polypropylene-polyethylene blends as matrices for wood flour-plastic composites. Composites Part A: Applied Science and Manufacturing, 41, 1559-1569 (2010).

https://doi.org/10.1016/j.compositesa.2010.07.002

[31] Oksman K.: Improved interaction between wood and synthetic polymers in wood/polymer composites. Wood Science and Technology, 30, 197-205 (1996). https://doi.org/10.1007/BF00231633 
[32] Oksman K., Clemons C.: Mechanical properties and morphology of impact modified polypropylene-wood flour composites. Journal of Applied Polymer Science, 67, 1503-1513 (1998).

https://doi.org/10.1002/(SICI)10974628(19980228)67:9<1503::AID-APP1>3.0.CO;2-H

[33] Park B-D., Balatinecz J. J.: Mechanical properties of wood-fiber/toughened isotactic polypropylene composites. Polymer Composites, 18, 79-89 (1997).

https://doi.org/10.1002/pc.10263

[34] Iwamoto S., Yamamoto S., Lee S-H., Ito H., Endo T.: Mechanical and thermal properties of polypropylene composites reinforced with lignocellulose nanofibers dried in melted ethylene-butene copolymer. Materials, 7, 6919-6929 (2014). https://doi.org/10.3390/ma7106919

[35] Sudár A., Renner K., Móczó J., Lummerstorfer T., Burgstaller C., Jerabek M., Gahleitner M., Doshev P., Pukánszky B.: Fracture resistance of hybrid PP/elastomer/wood composites. Composite Structures, 141, 146-155 (2016). https://doi.org/10.1016/j.compstruct.2016.01.031

[36] Spahr D. E., Friedrich K., Schultz J. M., Bailey R. S.: Microstructure and fracture behaviour of short and long fibre-reinforced polypropylene composites. Journal of Materials Science, 25, 4427-4439 (1990). https://doi.org/10.1007/BF00581104

[37] Karger-Kocsis J.: Instrumented impact fracture and related failure behavior in short- and long-glass-fiber-reinforced polypropylene. Composites Science and Technology, 48, 273-283 (1993).

https://doi.org/10.1016/0266-3538(93)90144-6

[38] Rohde M., Ebel A., Wolff-Fabris F., Altstädt V.: Influence of processing parameters on the fiber length and impact properties of injection molded long glass fiber reinforced polypropylene. International Polymer Processing, 26, 292-303 (2011).

https://doi.org/10.3139/217.2442
[39] Bárány T., Izer A., Czigány T.: On consolidation of selfreinforced polypropylene composites. Plastics, Rubber and Composites, 35, 375-379 (2006).

https://doi.org/10.1179/174328906X128234

[40] Zbončák M., Jančář J.: Toughening of PMMA by short poly(P-phenylene-2,6-benzobisoxazole) fibers. Express Polymer Letters, 12, 753-766 (2018).

https://doi.org/10.3144/expresspolymlett.2018.64

[41] Sobczak L., Jerabek M., Lummerstorfer T., Salaberger D., Renner K., Haider A.: Pseudo-ductile behaviour of poly(vinyl alcohol) fibre reinforced polypropylene. Submitted to Composites Part A: Applied Science and Manufacturing (2019).

[42] Santos P., Pezzin S. H.: Mechanical properties of polypropylene reinforced with recycled-PET fibres. Journal of Materials Processing Technology, 143-144, 517-520 (2003). https://doi.org/10.1016/S0924-0136(03)00391-1

[43] Doshev P., Lohse G., Henning S., Krumova M., Heuvelsland A., Michler G., Radusch H-J.: Phase interactions and structure evolution of heterophasic ethylene-propylene copolymers as a function of system composition. Journal of Applied Polymer Science, 101, 2825-2837 (2006).

https://doi.org/10.1002/app.22921

[44] Pukánszky B.: Effect of interfacial interactions on the deformation and failure properties of $\mathrm{PP} / \mathrm{CaCO}_{3}$ composites. New Polymeric Materials, 3, 205-217 (1992).

[45] Renner K., Kenyó C., Móczó J., Pukánszky B.: Micromechanical deformation processes in PP/wood composites: Particle characteristics, adhesion, mechanisms. Composites Part A: Applied Science and Manufacturing, 41, 1653-1661 (2010). https://doi.org/10.1016/j.compositesa.2010.08.001

[46] Renner K., Móczó J., Pukánszky B.: Deformation and failure of PP composites reinforced with lignocellulosic fibers: Effect of inherent strength of the particles. Composites Science and Technology, 69, 1653-1659 (2009). https://doi.org/10.1016/j.compscitech.2009.03.015 